gyptian J. Anim. Prod. (2011) 48(1)27-39.

\title{
THERMAL RESPONSES AND RESPIRATORY ACTIVITIES OF SHEEP UNDER HEAT STRESS AS AFFECTED BY SOME DIETARY SALTS
}

\author{
T. M. M. Abdel khalek ${ }^{1}$, A.K.I. Abd El-Moty ${ }^{2}$, M. A. A. El-Barody ${ }^{2}$ and \\ A. A. K. Saleh ${ }^{1}$
}

1- Animal production Research Institute, Agriculture Research Center, Ministry of Agriculture, 2- Animal Production Department, Faculty of Agriculture, Minia University

\section{SUMMARY}

Thirty five ewes and fifteen Farafra mature sheep rams were used in this investigation. The experimental animals (rams and ewes) were divided into five equal groups ( 7 ewes +3 rams per each) according to their age and initial body weight as control, $1 \%$ sodium bicarbonate $\left(G_{1}\right), 1 \%$ potassium carbonate $\left(G_{2}\right), 0.5 \%$ sodium bicarbonate $+0.5 \%$ potassium carbonate $\left(G_{3}\right)$ and finally $1 \%$ sodium bicarbonate + $1 \%$ potassium carbonate $\left(G_{4}\right)$. The concentrate mixture was extremely machinery mixed with the salt additives. Ambient temperature and relative humidity were recorded simultaneously at morning and at afternoon during experimental period (June to August). Thermal responses (rectal temperature, skin temperature and ear temperature) in both rams and ewes measured at morning and at afternoon during experimental period. Respiratory activates and gas exchanges were determined three times (at 15/June, 15/July and 15/August) in both rams and ewes throughout experimental period. The results indicated that treated rams and ewes decreased significantly $(P<0.01)$ their rectal temperature $(R T)$, skin temperature $(S T)$ at morning (6-8 a.m) and at afternoon (12-2 p.m). As well as, they decreased significantly $(P<0.01)$ respiration rate $(R R)$. Dietary salts resulted insignificantly decreases in ear temperature (ET) of ewes at morning and significantly decreases $(P<0.05)$ ET in rams. At afternoon ET decreased significantly $(P<0.05)$ in both treated rams and ewes. Gas volume $(G V)$, tidal volume $(T V)$ and volume of oxygen consumption $\left(\mathrm{VO}_{2}\right)$ increased significantly $(P<0.05)$ by dietary salts and decreased insignificantly volume of carbon dioxide production $\left(\mathrm{VCO}_{2}\right)$ in both rams and ewes. Also, dietary salts decreased significantly $(P<0.01)$, respiratory quotient $(R Q)$ in both rams and ewes. From the present results it can be concluded that dietary salts alleviated significantly body temperature by decreasing RT, ST and affected beneficially gas exchange parameters.

Keywords: Thermal responses, Respiratory Activities, Dietary Salts, Heat Stress, sheep 